\title{
Genetic basis of differences in myxospore count between whirling disease-resistant and -susceptible strains of rainbow trout
}

\author{
Eric R. Fetherman ${ }^{1, *}$, Dana L. Winkelman ${ }^{2}$, George J. Schisler ${ }^{1}$, Michael F. Antolin ${ }^{3}$ \\ ${ }^{1}$ Colorado Parks and Wildlife, 317 West Prospect Street, Fort Collins, Colorado 80523, USA \\ ${ }^{2}$ US Geological Survey, Colorado Cooperative Fish and Wildlife Research Unit, Department of Fish, Wildlife and \\ Conservation Biology, Colorado State University, Fort Collins, Colorado 80523, USA \\ ${ }^{3}$ Department of Biology, Colorado State University, Fort Collins, Colorado 80523, USA
}

\begin{abstract}
We used a quantitative genetics approach and estimated broad sense heritability $\left(h^{2}{ }_{b}\right)$ of myxospore count and the number of genes involved in myxospore formation to gain a better understanding of how resistance to Myxobolus cerebralis, the parasite responsible for whirling disease, is inherited in rainbow trout Oncorhynchus mykiss. An M. cerebralis-resistant strain of rainbow trout, the German Rainbow (GR), and a wild, susceptible strain of rainbow trout, the Colorado River Rainbow (CRR), were spawned to create 3 intermediate crossed populations (an F1 cross, F2 intercross, and a B2 backcross between the F1 and the CRR). Within each strain or cross, $h^{2}{ }_{b}$ was estimated from the between-family variance of myxospore counts using full-sibling families. Estimates of $h^{2}{ }_{b}$ and average myxospore counts were lowest in the GR strain, F1 cross, and F2 intercross $\left(h_{b}^{2}=0.34,0.42\right.$, and $0.34 ;$ myxospores fish ${ }^{-1}=275,9566$, and 45780 , respectively), and highest in the B2 backcross and CRR strain $\left(h^{2}{ }_{b}=0.93\right.$ and $0.89 ;$ myxospores fish ${ }^{-1}=97865$ and 187595 , respectively). Comparison of means and a joint-scaling test suggest that resistance alleles arising from the GR strain are dominant to susceptible alleles from the CRR strain. Resistance was retained in the intermediate crosses but decreased as filial generation number increased (F2) or backcrossing occurred (B2). The estimated number of segregating loci responsible for differences in myxospore count in the parental strains was $9 \pm 5$. Our results indicate that resistance to $M$. cerebralis is a heritable trait within these populations and would respond to either artificial selection in hatcheries or natural selection in the wild.
\end{abstract}

KEY WORDS: Myxobolus cerebralis $\cdot$ Oncorhynchus mykiss $\cdot$ Parasite $\cdot$ Salmonid $\cdot$ Heritability Quantitative genetics

Resale or republication not permitted without written consent of the publisher

\section{INTRODUCTION}

Infection with Myxobolus cerebralis, the parasite responsible for salmonid whirling disease, is the primary factor causing recruitment failure and population collapses in rainbow trout Oncorhynchus mykiss fisheries throughout the Intermountain West, USA (Walker \& Nehring 1995, Nehring \& Walker 1996, Schisler et al. 1999a,b, Nehring \& Thompson 2001). Due to the complex life cycle of the parasite and its durability in the environment, control of the parasite in wild trout populations is problematic. One promising avenue for managing trout populations in the presence of the parasite is the propagation and release of genetically resistant rainbow trout (Price 1985, Schisler et al. 2006).

Intentionally and unintentionally, hatchery managers have increased disease resistance in fish stocks through the continued propagation of survivors of disease as brood stock (Herman 1970); this selection 
process presumably led to the production of hatchery-derived rainbow trout strains that are resistant to Myxobolus cerebralis. El-Matbouli et al. (2002) found that, under experimental laboratory conditions, a German strain of rainbow trout (German Rainbow, GR) was at least as resistant to $M$. cerebralis as brown trout Salmo trutta, which evolved with the parasite in its European home range (Hoffman 1970). The GR strain was also found to be more resistant to M. cerebralis than either the North American Trout Lodge (TL) or Colorado River Rainbow (CRR) trout strains (Hedrick et al. 2003, Schisler et al. 2006). Resistance likely arose through the growth and reproduction of the GR strain under continuous exposure to the parasite in Bavarian hatcheries (Hedrick et al. 2003).

Resistance to disease in animals is often a complex, polygenic trait (Grenfell \& Dobson 1995) that results from a series of complex interactions among the host, pathogen, and environment (Snieszko 1974, Hedrick 1998). The mechanisms for resistance to Myxobolus cerebralis seen in the GR strain, like those seen in trout resistant to a similar myxosporean, Ceratomyxa shasta, are suspected to be polygenic (Hedrick et al. 2001). Studies examining differential gene expression in resistant and susceptible strains of rainbow trout have identified several genes potentially involved in resistance (Severin \& El-Matbouli 2007, Baerwald et al. 2008, Severin et al. 2010). Baerwald et al. (2011) discovered a major quantitative trait locus (QTL) influencing resistance that explains between 50 and $86 \%$ of the genetic variation relating to resistance in the GR strain, indicating that a single large-effect gene confers the bulk of the resistance in the hatchery-selected strain. However, other minoreffect genes may also be contributing, as at least one other QTL was identified by Baerwald et al. (2011), and a microarray gene expression study found upregulation of the metallothionein-B gene in the same strain (Baerwald et al. 2008). Until specific genetic and immune mechanisms of resistance are known, we must rely on multiple approaches to explore how resistance is inherited. Such approaches may include selectively breeding disease-resistant populations and using quantitative genetic experiments to measure heritability within fish brood stocks (Price 1985).

Heritabilities are used as a guide for predicting the response to selection when certain individuals are spawned, and how selected traits will change in subsequent generations. Heritability estimates the proportion of phenotypic variation in a population that may be attributed to genetic causes. Statistical and experimental techniques for estimating heritability are well known and are often used in selective breeding programs (Becker 1992, Falconer \& MacKay 1996, Lynch \& Walsh 1998). The objective of our study was to gain a better understanding of how whirling disease resistance characteristics were inherited in rainbow trout. We used a quantitative genetics approach to estimate broad sense heritability $\left(h^{2}{ }_{b}\right)$ of myxospore count, a measure of susceptibility to Myxobolus cerebralis, and the number of genes involved in myxospore formation (Becker 1992, Lynch \& Walsh 1998).

\section{MATERIALS AND METHODS}

\section{Brood stock development}

In 2004, the Colorado Division of Wildlife (CDOW) began a selective breeding program using the hatchery-selected GR strain and the CRR strain, a wild rainbow trout strain that had been historically used to establish rainbow trout populations in Colorado (Schisler et al. 2006). The CRR strain is susceptible to infection by Myxobolus cerebralis and has experienced severe population declines in areas where the disease has been introduced (Nehring \& Thompson 2001). Resistant GR fish were crossed with susceptible CRR fish to incorporate whirling disease resistance from the GR strain into a population that retained many of the desired characteristics influencing the ability to survive and reproduce in the wild, which may have been lost in the highly domesticated GR strain (Schisler et al. 2006). Besides being domesticated, the GR strain is inbred and exhibits low heterozygosity (El-Matbouli et al. 2006), which may compromise its survival and adaptation in natural environments. Brood stocks developed during earlier studies were used to create the populations evaluated in this study.

\section{Generation of experimental population}

The experimental families examined in our study were spawned at the CDOW Bellvue Fish Research Hatchery (BFRH). Experimental fish included those from the original resistant GR and susceptible CRR parental strains, with crossing between the two to generate an F1 population, intercrosses among F1 fish to create an F2 population, and backcrosses between the F1 cross and CRR strain to create a B2 population. For each parental strain and crossed population, replicate full-sibling families were spawned 
from unique male-female pairings to maintain a diverse experimental population. Offspring of each family were kept separate throughout the rearing process.

Eggs were placed in incubators at the BFRH or Colorado Cooperative Fish and Wildlife Research Unit (CFWRU) wet lab and held until they were eyed. Once eyed, eggs were placed in 761 (20 gallon) flowthrough tanks $\left(0.51 \mathrm{~min}^{-1}\right)$, supplied by a combination of well water and charcoal-filtered municipal water, at the CFWRU wet lab where they were hatched.

\section{Myxobolus cerebralis exposure experiment}

\section{Laboratory design}

In the exposure experiment, 100 tanks were used, each containing one family. A full-sibling design was chosen to complete both the exposure experiment and to meet other experimental goals for testing physiological responses to parasite exposure (Fetherman et al. 2011). A group of 80 full-sibling families was exposed to Myxobolus cerebralis and comprised 10 GR families, 10 CRR families, 20 F1 families, 20 F2 families, and 20 B2 families. The 20 F1 families were spawned from 10 CRR males individually crossed with GR females, and reciprocally, 10 GR males crossed with CRR females. The 20 B2 families were spawned from 10 CRR males individually crossed with F1 females, and reciprocally, 10 F1 males crossed with CRR females. Reciprocal families were included to test for differences in myxospore count following exposure to the pathogen, based on directionality of spawning. F2 intercross families were spawned from F1 males individually crossed with F1 females. As a result of both parents of an F2 intercross family originating from F1 cross fish, reciprocal families could not be created; replicate F2 families were used to equalize sample sizes among experimental populations (20 families each of the F1, F2, and B2 crosses). Due to a restriction on the number of brood stock available for spawning, only 80 total families could be tested. Ten exposed families per strain were needed to calculate heritability (a priori power calculation based on an additive genetic model of inheritance; Lynch \& Walsh 1998), and space constraints limited the number of tanks that could be accommodated.

Prior to exposure, 4 families from each parental strain or cross were split and used as both exposed and unexposed control families, for a total of 20 unexposed control families. Unexposed families were placed together on the top shelf of a 2-tier shelving unit to avoid potential contamination due to overflow and spills from exposure tanks. Otherwise, exposed and unexposed families were randomly assigned to tanks, with 25 fish $\operatorname{tank}^{-1}$, using a random number generator.

\section{Pathogen exposure}

In each of the 80 exposure tanks, 25 fish were exposed to Myxobolus cerebralis at an average $( \pm \mathrm{SD})$ of $678( \pm 44)$ degree-days $\left({ }^{\circ} \mathrm{C}\right)$ post-hatch (following Schisler et al. 2006), and an average age of 9.8 $( \pm 1.0)$ wk post-hatch. Mean individual weights $(\mathrm{g})$ at exposure were 0.67 for $G R, 0.49$ for $C R R, 0.71$ for $F 1$, 0.51 for F2, and 0.55 for B2 (Fetherman et al. 2011). The GR, CRR, F2, and B2 did not differ in mean weight at exposure; however, F1 hybrids were significantly larger than the F2, B2, and CRR fish (see Fetherman et al. 2011 for statistical details).

Triactinomyxons (TAMs), the infectious waterborne stage of Myxobolus cerebralis, were produced using Mt. Whitney Tubifex tubifex (origin, Mount Whitney Fish Hatchery, Lone Pine, California, USA). The concentration of viable TAMs was estimated by mixing $1000 \mu \mathrm{l}$ of filtrate containing the TAMs and $60 \mu \mathrm{l}$ of crystal violet; $84.6 \mu \mathrm{l}$ of this mixture was then placed on a slide and the number of TAMs per slide was counted. Ten counts per filtrate were conducted in this fashion to account for a possible uneven distribution of the TAMs within the filtrate. An average of the 10 counts was taken, and this number was used to calculate TAMs ml ${ }^{-1}$ of culture. Fish were infected with 2000 TAMs ind. $^{-1}$, for a total of 50000 TAMs $\operatorname{tank}^{-1}\left(\sim 715\right.$ TAMs $\left.^{-1}\right)$.

Prior to the addition of TAMs, water flow to each aquarium was stopped for $1 \mathrm{~h}$, and each aquarium received aeration to ensure mixing of the TAMs and even exposure of all fish. The amount of filtrate needed to deliver 50000 TAMs was added to each aquarium in 2 doses, each dose containing half of the necessary filtrate. Using 2 doses helped ensure equal distribution of TAMs in the tank and accounted for a possible unequal distribution of TAMs within the filtrate. Variation in propagation of the disease among tanks was not possible because the secondary host (Tubifex tubifex) was not present in the experimental system. As a control, 20 tanks, 4 replicate tanks containing a family from each of the 5 parental strains or crosses, were not exposed to the pathogen, but were treated in the same manner as the exposure tanks. 
After exposure, fish were reared for approximately 6 mo to ensure the full development of myxospores. During this time, developing signs of disease and mortalities were recorded daily, and the effects of Myxobolus cerebralis exposure on growth and swimming performance were also evaluated (Fetherman et al. 2011).

\section{Post-exposure evaluations}

Exposure evaluations began when fish reached approximately 2240 ( \pm 38) degree-days $\left({ }^{\circ} \mathrm{C}\right)$ postexposure. At the time of evaluation, 10 individuals from each tank were removed, sacrificed using an overdose of tricane methanesulfonate (MS-222), and used for myxospore enumeration (O'Grodnick 1975) using the pepsin-trypsin digest method (Markiw \& Wolf 1974). The heads were severed from the body just behind the operculum and pectoral fins, placed into individually labeled bags, and sent to the CDOW Brush Fish Health Laboratory in Brush, Colorado, USA, for myxospore enumeration. Lengths $(\mathrm{cm})$ and weights ( $g$ ) were recorded for each individual at the time of evaluation. Percent mortality occurring between exposure and evaluation was calculated for each parental strain or cross.

\section{Statistical analyses}

Statistical analyses were conducted using SAS Proc GLM (SAS Institute 2008). Myxospore counts were analyzed using a 2-factor analysis of variance (ANOVA), with exposure and parental strain or cross as factors. Mortality percentages were arcsine-square root transformed prior to analysis. Transformed values were then analyzed using a 2-factor ANOVA, with exposure and parental strain or cross as factors. Values for all analyses were reported from the Type III sum of squares to account for the unbalanced design of the experiment. If significant main effects were identified ( $\mathrm{p} \leq 0.05)$, a Bonferroni adjusted least squares means method was used to determine which parental strain or cross differed from the others.

\section{Quantitative genetics approach}

\section{Heritability}

Broad-sense heritability $\left(h^{2}{ }_{b}\right)$ of myxospore count following exposure to Myxobolus cerebralis was cal- culated using a random, single-pair mating design (Becker 1992) within each unique parental strain (GR, CRR) and crossed population (F1, F2, B2). Singlepair mating generated full-sibling families, and heritability was estimated using covariance in traits within full-sibling families $\left(C O V_{\mathrm{FS}}\right)$. This covariance includes half of the additive variance $\left(V_{\mathrm{A}}\right)$, one-fourth of the dominance variance $\left(V_{\mathrm{D}}\right)$, and the variance arising from a common environment ( $V_{\mathrm{EC}}$; Becker 1992, Falconer \& MacKay 1996).

Heritability was estimated from variance components $\sigma^{2}{ }_{\mathrm{w}}$ and $\sigma^{2}{ }_{\mathrm{s}}$, calculated from ANOVA as $\sigma^{2}{ }_{\mathrm{w}}=$ $M S_{\mathrm{W}}$, and $\sigma^{2}{ }_{\mathrm{s}}=\left(M S_{\mathrm{S}}-M S_{\mathrm{W}}\right) / k$ (see Table 1$) . M S_{\mathrm{W}}$ is the mean squared error of myxospore counts associated with variance among progeny within families, and $M S_{\mathrm{S}}$ is the mean squared error among families. Both $M S_{\mathrm{S}}$ and $M S_{\mathrm{W}}$ were estimated using ANOVA, with $k$ individuals in each family (Becker 1992). In our case $k=10$, which, though low, lies within the range of acceptable $k$ for calculating heritability (Lynch \& Walsh 1998). Heritability was calculated as $h^{2}{ }_{\mathrm{b}}=\left(2 \sigma^{2}{ }_{\mathrm{s}}\right) /\left(\sigma_{\mathrm{w}}^{2}+\sigma_{\mathrm{s}}^{2}\right)$, with standard errors and $95 \%$ confidence intervals calculated following Becker (1992). Myxospore counts were $\log _{10}$-transformed to normalize the data prior to performing quantitative genetic analyses.

\section{Modes of inheritance}

A joint-scaling test (Lynch \& Walsh 1998) was used to calculate expected myxospore counts $\left(\chi^{2}\right.$ statistic using $\log _{10}$-transformed myxospore count) in each of the crosses and the GR and CRR parental strains based on purely additive (A) and additive-dominance (AD) models of inheritance. Given a priori expectations for myxospore count based on a purely additive model, a joint-scaling test determines whether observed values deviate from those expected, and whether the additive or additive-dominance model better describes the mode of inheritance for a given trait (Lynch \& Walsh 1998).

The resistant GR strain was expected to exhibit low myxospore count with small variance, resulting in low heritability estimates, because resistant alleles were expected to be nearly fixed in this strain. The CRR strain was expected to exhibit high myxospore counts, also with small variance, because resistance should be minimal based on previous laboratory exposure trials by Schisler et al. (2006). The F1 cross was expected to exhibit low variation and a response intermediate to the GR and CRR strains, because F1 individuals should be heterozygous for resistant 
alleles from the GR and susceptible alleles from the CRR. If resistance alleles displayed dominance, however, the myxospore counts in the F1 would be similar to the GR. The F2 intercross population was expected to exhibit a similar average myxospore count as the F1 cross fish, but with higher variance due to segregation and recombination of GR and CRR parental genes among F2 individuals. Finally, the B2 backcross between F1s and CRRs was expected to exhibit intermediate myxospore counts and variance, again due to segregation and recombination of parental alleles.

\section{Number of independently segregating loci}

Analysis of line crosses was used to estimate the effective number of segregating loci $\left(n_{\mathrm{e}}\right)$ responsible for differences in myxospore counts between the GR and CRR strains. Low $n_{\mathrm{e}}$ values suggest that relatively few genes on relatively few chromosomes underlie the differences, and higher values suggest that genes are spread over many chromosomes (Lynch \& Walsh 1998).

Composite effects, which characterize additive and dominance genetic effects responsible for differences between parental strains and crosses, were calculated using the $\log _{10}$-transformed myxospore counts. Composite effects were used to estimate $n_{\mathrm{e}}$ and its standard error using the Castle-Wright estimator,

$$
n_{\mathrm{e}}=\frac{\left[\bar{z}\left(P_{1}\right)-\bar{z}\left(P_{2}\right)\right]-\operatorname{Var}\left[\bar{z}\left(P_{1}\right)\right]-\operatorname{Var}\left[\bar{z}\left(P_{2}\right)\right]}{8 \operatorname{Var}(S)}
$$

where $\bar{Z}\left(P_{\mathrm{t}}\right)$ are the observed means, $\operatorname{Var}\left[\bar{Z}\left(P_{\mathrm{t}}\right)\right]$ are the sampling variances of the means for the $i$ th parental line, and $\operatorname{Var}(S)$ is the segregational variance estimate (Lynch \& Walsh 1998).

The assumption of independent assortment among loci was tested using haploid chromosome number ( $N=29$; Hartley \& Horne 1982, Thorgaard 1983, Ocalewicz et al. 2004) and genetic linkage maps (Young et al. 1998, Sakamoto et al. 2000, Nichols et al. 2003) for rainbow trout. The average haploid chromosome number of 29 was chosen as representative for the rainbow trout population used in this study; however, due to polymorphism (Thorgaard 1983), haploid chromosome number in rainbow trout is known to vary from this average (Guyomard et al. 2006). The average recombination frequency between loci influencing the trait $\bar{C}$ was estimated to test for independent assortment, using the equation

$$
\bar{C}=\frac{M-1}{2 M}
$$

where $M$ is the haploid chromosome number (29). The maximum value $\bar{C}=0.5$ indicates independent assortment, with lower values indicating linkage among genes on a chromosome (Lynch \& Walsh 1998)

\section{RESULTS}

\section{Exposure metrics}

Mean myxospore count differed among parental strains and crosses $\left(F_{4,793}=61.39, \mathrm{p}<0.001\right.$; Fig. 1$)$. CRR individuals had the highest mean myxospore count (187595 myxospores fish ${ }^{-1}$ ), and largest variation in myxospore count (SD $=115355)$. Mean myxospore count did not differ among F1 and GR fish (9566 and 275 myxospores fish ${ }^{-1}$, respectively), as expected if resistance alleles from the GR strain are dominant. GR fish showed the lowest variation in myxospore count (SD = 464; Fig. 1). F2 fish had a significantly higher mean myxospore count (45780 myxospores fish ${ }^{-1}$ ) than the F1 or GR, with more than double the variation in myxospore count $(\mathrm{SD}=$ 40816 ) than F1 fish (SD = 14 164). As expected if resistance alleles differed between the GR and CRR parental strains, the B2 fish exhibited a higher

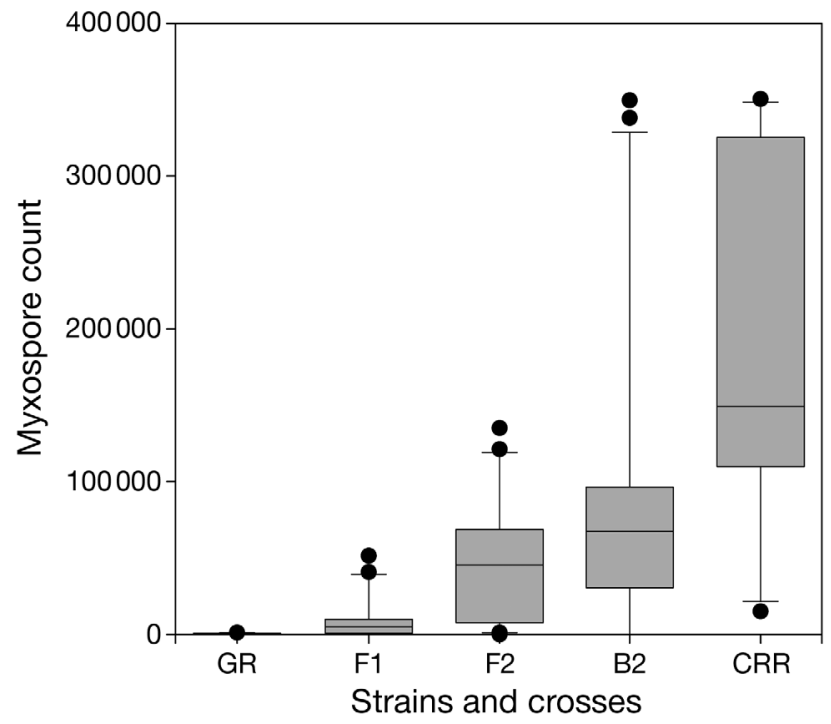

Fig. 1. Oncorhynchus mykiss. Myxospore count distribution for the 2 parental strains (German Rainbow, GR; Colorado River Rainbow; CRR) and crossed populations (F1, F2, B2) exposed to Myxobolus cerebralis. The box plots display the distribution of the mean myxospore counts per family within a strain or cross, with 10 families represented in the GR and CRR parental strains and 20 families represented in the F1, F2, and B2 crosses. Boxes: 25th and 75th percentiles; bars: 10th and 90th percentiles; dots: outliers 
myxospore count (97865 myxospores fish ${ }^{-1}$ ), and larger variation in myxospore counts $(\mathrm{SD}=102362)$, than the GR, F1, or F2 fish.

Myxospore counts differed among families of the CRR strain and the F1 cross, F2 intercross, and B2 backcross ( $\mathrm{p} \leq 0.001)$. No differences were seen among GR strain families $(p=0.183)$. No differences were seen between reciprocal families of the F1 cross $(p=0.117)$ or B2 backcross $(p=0.233)$, indicating that myxospore count is not influenced by maternal effects or other sex-linked genetic factors. Fish from unexposed control families did not develop myxospores.

Mortality did not differ between exposed and unexposed fish or among parental strains and crosses $\left(F_{9,88}=1.38, \mathrm{p}=0.210\right)$. Average mortality was low, $2.6 \%$ in unexposed control fish and $6.6 \%$ in exposed fish (Fetherman et al. 2011).

\section{Quantitative genetics}

\section{Heritability}

Variation in myxospore count, both within and between families, indicated that broad-sense heritability $\left(h^{2}{ }_{\mathrm{b}}\right)$ was estimable for all strains and crosses. Because reciprocal families in the F1 cross and B2 backcross did not differ (see above), all families of these crosses were used in heritability calculations. The GR strain, and F1 and F2 crosses had relatively low $h^{2}{ }_{\mathrm{b}}$ estimates, while the B2 backcross had a higher $h^{2}{ }_{\mathrm{b}}$ estimate (Table 1). Interestingly, the CRR strain $h^{2}$ bas also greater than either the F1 or F2 crosses (Table 1).

Table 1. Oncorhynchus mykiss. Variance components $\left(\sigma^{2}{ }_{s}\right.$ and $\sigma^{2}{ }_{w}$ ) for $\log _{10}$-transformed myxospore counts, broad sense heritability estimates $\left(h^{2}{ }_{b}\right)$ of myxospore count as a result of exposure to Myxobolus cerebralis, standard errors (in parentheses, representing $2 \mathrm{SE}_{i}$ Becker 1992), and $95 \%$ confidence intervals (CI, mean $\pm 2 \mathrm{SE}$ ), for the parental strains (German Rainbow, GR; Colorado River Rainbow, CRR; $\mathrm{N}=$ 10 each) and crosses ( $\mathrm{N}=20$ each) of rainbow trout used in the $M$. cerebralis exposure experiment

\begin{tabular}{|lcccc|}
\hline Strain/cross & $\sigma^{2}{ }_{\mathrm{s}}$ & $\sigma^{2}{ }_{\mathrm{w}}$ & $\begin{array}{c}h^{2}{ }_{\mathrm{b}} \text { Myxospore } \\
\text { count }\end{array}$ & $95 \% \mathrm{CI}$ \\
\hline GR strain & 0.14 & 0.68 & $0.34(0.21)$ & $(0.13,0.55)$ \\
F1 cross & 0.84 & 3.20 & $0.42(0.23)$ & $(0.19,0.64)$ \\
F2 intercross & 0.90 & 4.64 & $0.34(0.21)$ & $(0.13,0.55)$ \\
B2 backcross & 2.54 & 2.90 & $0.93(0.28)$ & $(0.66,1.21)$ \\
CRR strain & 0.33 & 0.69 & $0.89(0.28)$ & $(0.61,1.17)$ \\
\hline
\end{tabular}

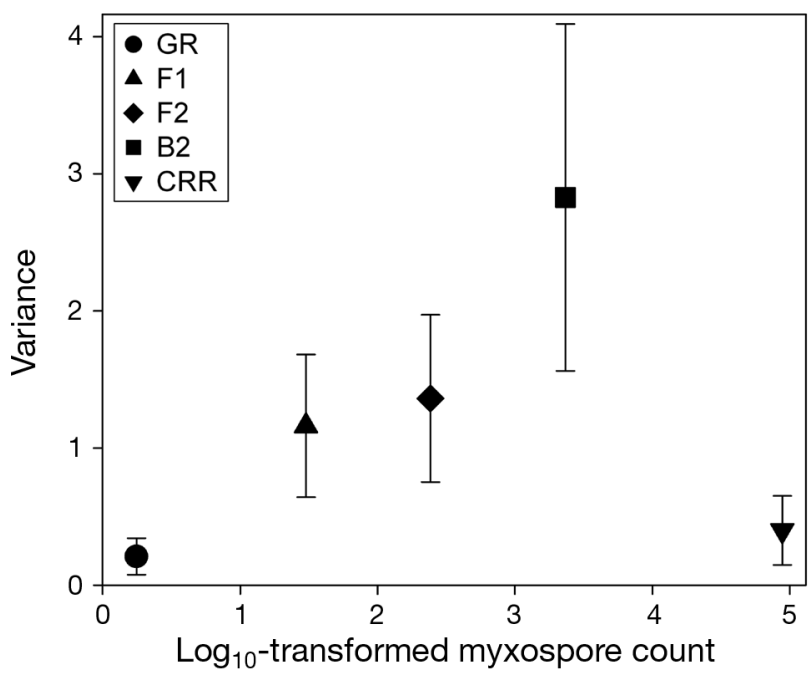

Fig. 2. Oncorhynchus mykiss. Line variance $( \pm 2 \mathrm{SE})$ versus $\log _{10}$-transformed myxospore count for each of the parental strains (German Rainbow, GR; Colorado River Rainbow, CRR) and crosses exposed to Myxobolus cerebralis. Notice that the outline of the form made by connecting the variances plotted against myxospore counts should be a triangle with F2 at the apex, but that variance of the B2 cross is greater than expected from a pure additive model, suggesting that dominance genetic variance may have also influenced myxospore counts in this $M$. cerebralis exposure experiment (Lynch \& Walsh 1998)

\section{Modes of inheritance}

Joint-scaling tests of means and variances of myxospore counts ( $\log _{10}$-transformed) in the parental strains and crosses indicated that values did not deviate from the expectations of either additive $\left(\chi_{\mathrm{A}, \mathrm{df}=3}^{2}=\right.$ $3.19, \mathrm{p}=0.36)$ or additive-dominance $\left(\chi_{\mathrm{AD}, \mathrm{df}=2}^{2}=0.19\right.$, $\mathrm{p}=0.91$ ) modes of inheritance (Fig. 2), and that the 2 modes could not be distinguished from each other $(\mathrm{p}=0.084)$.

\section{Number of independently segregating loci}

The effective number of factors $\left(n_{\mathrm{e}}\right)$ by which the GR and CRR strains differed in relation to myxospore count was $9 \pm 5$. The estimate of recombination among loci was $\bar{C}=0.48$ (0.50 is considered independent segregation).

\section{DISCUSSION}

Our results indicate that resistance to Myxobolus cerebralis is a heritable trait and would respond to selection. Additionally, our joint-scaling analysis and 
estimated number of segregating factors suggest that relatively few loci $\left(n_{\mathrm{e}}=9\right)$ are involved in resistance to $M$. cerebralis in the GR strain. The patterns of variation, both within and among the parental strains and intermediate crosses, suggest that resistance alleles from the GR strain are dominant, that differences between the CRR and GR strains are heritable, and that the CRR strain is susceptible, but also genetically variable.

Although the GR strain was expected to have low heritability in myxospore count, because resistance alleles should be fixed, this strain nonetheless showed a significant $h^{2}$ b (Table 1). An overestimate of heritability may have arisen because common environmental variation between tanks influenced some families, i.e. tank effects may have arisen as a result of raising a single family in one tank. Although environmental variance can be considered small because environmental conditions, including temperature, water quality, and feed amount, were kept constant for all groups, it still likely influenced the estimates since the environment could not be completely controlled. Heritability estimates in the F1 cross and F2 intercross were similar to the GR strain, but $h^{2}{ }_{\mathrm{b}}$ was higher in the B2 backcross, suggesting that differences between families also had a genetic basis.

High $h^{2}{ }_{\mathrm{b}}$ in the CRR strain was unexpected because this strain was expected to show little variation in susceptibility alleles, and all families were expected to exhibit high myxospore counts. High $h^{2}{ }_{\mathrm{b}}$ indicates that the CRR is more variable for susceptibility alleles than expected and/or has evolved some level of resistance. CRR fish exhibited high variation in myxospore count in other laboratory experiments (Schisler et al. 2006, 2007), again indicating that some individuals have a degree of natural genetic resistance to the parasite. However, in both this and previous experiments, environmental factors may also have contributed to the variation in myxospore count. In the future, we suggest that narrow sense heritability of myxospore count be evaluated for the CRR strain, using a paternal half-sib mating design and larger sample sizes, to determine the additive genetic variance for the resistance trait; this could be coupled with an exposure experiment similar to the one described here to determine whether resistance is increasing in the CRR population as it continues to be exposed to whirling disease.

Overall, it appears that resistance to Myxobolus cerebralis can evolve in rainbow trout, either as a response to artificial selection in hatcheries or natural selection in the wild. Resistance in a similar rainbow trout population from Harrison Lake, Montana, USA, has increased in the wild with continued exposure to the parasite (Miller \& Vincent 2008). Miller \& Vincent (2008) suggested that as more resistant young from the population age and predominate during annual spawning events, it may be possible for the population to return to levels observed prior to parasite establishment. A similar response to selection would be expected in residual CRR populations; however, recovery is expected to be slow, given the low survival of $M$. cerebralis-infected fish in wild CRR populations (Nehring \& Thompson 2003). Quicker recovery could be facilitated with the introduction of one of the crosses examined in this study, for example, the F1 cross. If $\mathrm{F} 1$ fish were used in reintroductions, spawning between 2 F1 individuals (F2 offspring) would be most likely; however, there is a potential that F1 fish could spawn with residual CRR fish in some areas (B2 offspring). In both cases, our results suggest that offspring should exhibit a range of genetic variability for resistance, and it is expected that those offspring that survive exposure to $M$. cerebralis and recruit to the adult population would be those that exhibit the best combination of survival and resistance characteristics as a result of natural selection.

Development of Myxobolus cerebralis-resistant rainbow trout is still being evaluated, but quantitative genetic approaches and selective breeding programs have been used to change population characteristics in several other salmonid species. Challenge tests and selective breeding experiments for resistance to a similar myxosporean parasite of rainbow trout, Ceratomyxa shasta, indicated that resistance to C. shasta was also heritable (Hemmingsen et al. 1986, Ibarra et al. 1992, 1994), but that the mechanism of resistance is not the same for the 2 parasites (Hedrick et al. 2001). Heritability estimates indicate that selective breeding could facilitate an increase in resistance to salmon louse in Atlantic salmon Salmo salar (Kolstad et al. 2005). Selective breeding programs have also been used to increase resistance to furunculosis in brook trout Salvelinus fontinalis (Cipriano et al. 2002).

The line-crossing estimate of the number of segregating factors that account for the differences between the CRR and GR strains was $n_{e}=9( \pm 5)$. In this experiment, the number of freely segregating loci cannot exceed the number of independently segregating chromosomal segments $(108$; Hartley \& Horne 1982, Thorgaard 1983, Ocalewicz et al. 2004), or 2 to 3 times the haploid chromosome number $(29$; Hartley \& Horne 1982, Thorgaard 1983, Ocalewicz et al. 2004). Our estimate of average recombination 
between randomly-selected loci $(\overline{\mathrm{C}}=0.48)$ confirms independent segregation and that we are not likely underestimating the number of genes underlying resistance to Myxobolus cerebralis in rainbow trout; however, conclusions could change depending on haploid chromosome number used, if different from the average (Guyomard et al. 2006). Additionally, male rainbow trout have a lower mean rate of recombination in relation to females (e.g. Baerwald et al. 2011), thus the estimate of $n_{\mathrm{e}}$ may be low. This is not likely to have a large effect in this experiment, as the estimate of $n_{\mathrm{e}}(9)$ is much lower than the number of chromosomes in rainbow trout (29).

Our estimate of loci involved in resistance is also complementary to the previous study of Baerwald et al. (2011), who found one major QTL on chromosome Omy9 that explained 50 to $86 \%$ of the variance in resistance in 4 F2 mapping families derived from crosses between GR and CRR. We discuss 4 reasons that a single major gene probably underestimates the total genetic variation in resistance in rainbow trout. First, a candidate resistance gene identified in other studies of resistance to Myxobolus cerebralis does not generally map to the chromosomal region Omy9 (Baerwald et al. 2011; and see below). Second, trout tested by Baerwald et al. (2011) were at a younger age than ours, so the major gene may be especially influential through that stage of life, with additional genes having an effect later on. Third, the QTL study examined 4 F2 mapping families in depth (Baerwald et al. 2011). The greater number of families in our study (80) may have uncovered additional genetic variation that did not segregate in the 4 families in the QTL study. Fourth, significant variation among families (and $h_{\mathrm{b}}^{2}$ ) in the parental CRR strain, and among families of the F1 cross, F2 intercross, and B2 backcross, further point to the presence of additional genetic variation even within the CRR parental strain. A single large-effect gene may be conferring the bulk of the resistance, but our estimates indicate that other minor-effect genes also contribute.

Genetic mechanisms of resistance to Myxobolus cerebralis in rainbow trout continue to be investigated, with some evidence that transforming growth factor beta (Severin \& El-Matbouli 2007), metallothionein B (Baerwald et al. 2008), immune-regulatory genes arginase-2, and inducible nitric oxide synthase (Severin et al. 2010) may be involved. Our results suggest that these factors are part of an additive genetic mechanism of resistance to $M$. cerebralis in rainbow trout involving many minor-effect genes, and that a continued search for alleles involved in resistance is likely to be informative. Price (1985) suggested that once genotypes that confer resistance have been identified, measures to increase their frequency in the populations could be implemented, but cautions that extrapolating results from one environment to others may fail because genotypes may not confer high fitness in the same manner in different environments.

\section{CONCLUSIONS}

Resistance characteristics are important traits when considering rainbow trout population reestablishment and brood stock development. The low heritability of myxospore count of the GR strain indicates that introgressing genetic variation from the GR into wild populations may succeed in reestablishing and managing wild rainbow trout sport-fish populations where they were extirpated by whirling disease. Lower myxospore counts should also result in a reduction of the overall myxospore load in the drainages where these fish are introduced. Our and others' results suggest that F1 cross fish may be the best candidates for reintroducing rainbow trout because they may have an initial combination of resistance and wild rainbow trout characteristics that would favor survival in the wild (Schisler et al. 2006, 2007). The effects of exposure to Myxobolus cerebralis on the performance of important survivalrelated characteristics on the GR strain and F1 cross, the survival and reproductive characteristics of GR and F1 fish in a natural setting, and the survival and resistance characteristics of wild-produced offspring need further evaluation.

Acknowledgements. This work was sponsored in part by the Whirling Disease Foundation, the Colorado Division of Wildlife, and the Colorado Cooperative Fish and Wildlife Research Unit at Colorado State University. We thank T. McDowell and R. Hedrick of the University of CaliforniaDavis, and R. B. Nehring of the Colorado Division of Wildlife, for providing triactinomyxons for the experimental exposures; P. Schler and A. Avalos at the Colorado Division of Wildlife Bellevue Fish Research Hatchery, for helping with brood stock and strain development; and A. Zamora, B. Lankriet, and M. Catanese for laboratory assistance. M.F.A. was supported as a Sabbatical Scholar by the National Evolutionary Synthesis Center in Durham, NC, during part of this work. The use of trade names or products does not constitute endorsement by the US Government.

\section{LITERATURE CITED}

Baerwald MR, Welsh AB, Hedrick RP, May B (2008) Discovery of genes implicated in whirling disease infection and 
resistance in rainbow trout using genome-wide expression profiling. BMC Genomics 9:37

Baerwald MR, Petersen JL, Hedrick RP, Schisler GJ, May B (2011) A major effect quantitative trait locus for whirling disease resistance identified in rainbow trout (Oncorhynchus mykiss). Heredity 106:920-926

Becker WA (1992) Manual of quantitative genetics. Academic Enterprises, Pullman, WA

Cipriano RC, Marchant D, Jones TE, Schachte JH (2002) Practical application of disease resistance: a brook trout fishery selected for resistance to furunculosis. Aquaculture 206:1-17

El-Matbouli M, Hoffman RW, Küppers MP (2002) Identification of a whirling disease resistant strain of rainbow trout in Germany. In: Putting a fresh spin on whirling disease. Proc 8th Whirling Dis Symp. Whirling Disease Initiative, Bozeman, MT, p 29-32

El-Matbouli M, Oucible A, Severin V, Meyer U, Grabner D, Hedrick RP (2006) Data on the mechanisms associated with the resistance of Hofer- and wild rainbow trout strains to whirling disease. In: War of the whirlds. Proc 12th Whirling Dis Symp. Whirling Disease Initiative, Bozeman, MT, p 22-23

Falconer DS, MacKay TFC (1996) Introduction to quantitative genetics. Pearson Education Limited, Edinburgh Gate, Harlow

Fetherman ER, Winkelman DL, Schisler GJ, Myrick CA (2011) The effects of Myxobolus cerebralis on the physiological performance of whirling disease resistant and susceptible strains of rainbow trout. J Aquat Anim Health 23:169-177

Grenfell BT, Dobson AP (1995) Ecology of infectious disease in natural populations. Cambridge University Press, Cambridge

Guyomard R, Mauger S, Tabet-Canale K, Martineau S, Genet C, Krieg F, Quillet E (2006) A type I and type II microsatellite linkage map of rainbow trout (Oncorhynchus mykiss) with presumptive coverage of all chromosome arms. BMC Genomics 7:302

Hartley SE, Horne MT (1982) Chromosome polymorphism in the rainbow trout (Salmo gairdneri Richardson). Chromosoma 87:461-468

> Hedrick RP (1998) Relationships of the host, pathogen, and environment: implications for diseases of cultured and wild fish populations. J Aquat Anim Health 10:107-111

> Hedrick RP, McDowell TS, Mukkatira K, Georgiadis MP (2001) Salmonids resistant to Ceratomyxa shasta are susceptible to experimentally induced infections with Myxobolus cerebralis. J Aquat Anim Health 13:35-42

> Hedrick RP, McDowell TS, Marty GD, Fosgate GT, Mukkatira K, Myklebust K, El-Matbouli M (2003) Susceptibility of two strains of rainbow trout (one with suspected resistance to whirling disease) to Myxobolus cerebralis infection. Dis Aquat Org 55:37-44

Hemmingsen AR, Holt RA, Ewing RD, McIntyre JD (1986) Susceptibility of progeny from crosses among three stocks of Coho salmon to infection with Ceratomyxa shasta. Trans Am Fish Soc 115:492-495

Herman RL (1970) Prevention and control of fish diseases in hatcheries. In: Snieszko SF (ed) Symposium on diseases of fisheries and shellfishes. Special Publication 5. American Fisheries Society, Bethesda, MD, p 3-15

Hoffman GL (1970) Intercontinental and transcontinental dissemination and transfaunation of fish parasites with emphasis on whirling disease (Myxosoma cerebralis). In:
Snieszko SF (ed) Symposium on diseases of fisheries and shellfishes. Special Publication 5. American Fisheries Society, Bethesda, MD, p 69-81

Ibarra AM, Hedrick RB, Gall GAE (1992) Inheritance of susceptibility to Ceratomyxa shasta (Myxozoa) in rainbow trout and the effect of length of exposure on the liability to develop ceratomyxosis. Aquaculture 104: 217-229

Ibarra AM, Hedrick RP, Gall GAE (1994) Genetic analysis of rainbow trout susceptibility to the myxosporean Ceratomyxa shasta. Aquaculture 120:239-262

> Kolstad K, Heuch PA, Gjerde B, Gjedrem T, Salte R (2005) Genetic variation in resistance of Atlantic salmon (Salmo salar) to the salmon louse Lepeophtheirus salmonis. Aquaculture 247:145-151

Lynch M, Walsh B (1998) Genetics and analysis of quantitative traits. Sinauer, Sunderland, MA

Markiw ME, Wolf K (1974) Myxosoma cerebralis: isolation and centrifugation from fish skeletal elements - sequential enzymatic digestions and purification by differential centrifugation. J Fish Res Board Can 31:15-20

Miller MP, Vincent ER (2008) Rapid natural selection for resistance to an introduced parasite of rainbow trout. Evol Appl 1:336-341

Nehring RB, Thompson KG (2001) Impact assessment of some physical and biological factors in the whirling disease epizootic among wild trout in Colorado. Special Report 76. Colorado Division of Wildlife Aquatic Research, Fort Collins, CO

Nehring RB, Thompson KG (2003) Whirling disease risk assessment: the Colorado perspective. In: Managing the risk. Proc 9th Whirling Dis Symp. Whirling Disease Initiative, Bozeman, MT, p 31-32

Nehring RB, Walker PG (1996) Whirling disease in the wild: the new reality in the intermountain west. Fisheries 21: 28-32

> Nichols KM, Young WP, Danzmann RG, Robison BD and others (2003) A consolidated linkage map for rainbow trout (Oncorhynchus mykiss). Anim Genet 34: 102-115

O'Grodnick JJ (1975) Whirling disease Myxosoma cerebralis spore concentration using the continuous plankton centrifuge. J Wildl Dis 11:54-57

Ocalewicz K, Babiak I, Dobosz S, Nowaczyk J, Goryczko K (2004) The stability of telomereless chromosome fragments in adult androgenetic rainbow trout. J Exp Biol 207:2229-2236

- Price DJ (1985) Genetics of susceptibility and resistance to disease in fishes. J Fish Biol 26:509-519

Sakamoto T, Danzmann RG, Gharbi K, Howard P and others (2000) A microsatellite linkage map of rainbow trout (Oncorhynchus mykiss) characterized by large sexspecific differences in recombination rates. Genetics 155: 1331-1345

SAS Institute (2008) SAS system software: release 9.1. SAS Institute, Cary, NC

Schisler GJ, Bergersen EP, Walker PG (1999a) Evaluation of chronic gas supersaturation on growth, morbidity, and mortality of fingerling rainbow trout infected with Myxobolus cerebralis. N Am J Aquac 61:175-183

> Schisler GJ, Walker PG, Chittum LA, Bergersen EP (1999b) Gill ectoparasites of juvenile rainbow trout and brown trout in the upper Colorado River. J Aquat Anim Health 11:170-174

Schisler GJ, Myklebust KA, Hedrick RP (2006) Inheritance 
of Myxobolus cerebralis resistance among F1-generation crosses of whirling disease resistant and susceptible rainbow trout strains. J Aquat Anim Health 18:109-115

Schisler GJ, Schler PJ, Fetherman ER (2007) Salmonid disease studies. Federal aid in fish and wildlife restoration, job progress report. Colorado Division of Wildlife, Fish Research Section, Fort Collins, CO

Severin VI, El-Matbouli M (2007) Relative quantification of immune-regulatory genes in two rainbow trout strains, Oncorhynchus mykiss, after exposure to Myxobolus cerebralis, the causative agent of whirling disease. Parasitol Res 101:1019-1027

Severin VIC, Soliman H, El-Matbouli M (2010) Expression of immune regulatory genes, arginase-2 and inducible nitric oxide synthase (iNOS), in two rainbow trout (OnCo-

Editorial responsibility: Catherine Collins,

Aberdeen, UK rhynchus mykiss) strains following exposure to Myxobolus cerebralis. Parasitol Res 106:325-334

Snieszko SF (1974) The effects of environmental stress on outbreaks of infectious diseases of fishes. J Fish Biol 6: 197-208

Thorgaard GH (1983) Chromosomal differences among rainbow trout populations. Copeia 1983:650-662

Walker PG, Nehring RB (1995) An investigation to determine the cause(s) of the disappearance of young wild rainbow trout in the Upper Colorado River, in Middle Park, Colorado. Colorado Division of Wildlife, Denver, $\mathrm{CO}$

Young WP, Wheeler PA, Coryell VH, Keim P, Thorgaard GH (1998) A detailed linkage map of rainbow trout produced using double haploids. Genetics 148:839-850

Submitted: July 25, 2012; Accepted: October 14, 2012

Proofs received from author(s): December 18, 2012 